\title{
Relationship between degree of focal kyphosis correction and neurological outcomes for patients undergoing cervical deformity correction surgery
}

\author{
Clinical article
}

\author{
Matthew J. Grosso, B.S., ${ }^{1}$ Roy Hwang, M.D., ${ }^{2}$ Thomas Mroz, M.D., ${ }^{1}$ \\ Edward Benzel, M.D., ${ }^{1}$ ANd Michael P. STEInMetz, M.D. ${ }^{3,4}$ \\ ${ }^{1}$ Cleveland Clinic, Center for Spine Health, Cleveland, Ohio; ${ }^{2}$ Department of Neurosurgery, West Virginia \\ University, Morgantown, West Virginia; ${ }^{3}$ Department of Neuroscience, MetroHealth Medical Center; and \\ ${ }^{4}$ Department of Neurosurgery, Case Western Reserve University, Cleveland, Ohio
}

\begin{abstract}
Object. Reversal of the normal cervical spine curvature, as seen in cervical kyphosis, can lead to mechanical pain, neurological dysfunction, and functional disabilities. Surgical intervention is warranted in patients with sufficiently symptomatic deformities in an attempt to correct the deformed cervical spine. In theory, improved outcomes should accompany a greater degree of correction toward lordosis, although there are few data available to test this relationship. The purpose of this study is to determine if the degree of deformity correction correlates with improvement in neurological symptoms following surgery for cervical kyphotic deformity.

Methods. A retrospective review of 36 patients with myelopathic symptoms who underwent cervical deformity correction surgery between 2001 and 2009 was performed. Preoperative and postoperative radiographic findings related to the degree of kyphosis were collected and compared with functional outcome measures. The minimum follow-up time was 2 years.

Results. A significant relationship was observed between a greater degree of focal kyphosis correction and improved neurological outcomes according to the modified Japanese Orthopaedic Association (mJOA) score $(\mathrm{r}=-0.46$, $\mathrm{p}=0.032)$. For patients with severe neurological symptoms (mJOA score $<12$ ) a trend toward improved outcomes with greater global kyphosis correction was observed $(r=-0.56, p=0.057)$. Patients with an mJOA score less than 16 who attained lordosis postoperatively had a significantly greater improvement in total mJOA score than patients who maintained a kyphotic position (achieved lordosis: $2.7 \pm 2.0$ vs maintained kyphosis: $1.1 \pm 2.1, \mathrm{p}=0.044$ ).

Conclusions. The authors' results suggest that the degree of correction of focal kyphosis deformity correlates with improved neurological outcomes. The authors also saw a positive relationship between attainment of global lordosis and improved mJOA scores. With consideration for the risks involved in correction surgery, this information can be used to help guide surgical strategy decision making.

(http://thejns.org/doi/abs/10.3171/2013.2.SPINE12525)
\end{abstract}

\section{KEY WORDS • cervical deformity • kyphosis • correction}

$\mathrm{T}$ The normal lordotic curvature of the cervical spine is critical to maintaining sagittal alignment and spinal balance. ${ }^{9,17,18}$ The reversal of normal cervical curvature, as seen in kyphosis, can occur through a variety of mechanisms and can lead to mechanical pain, neurological dysfunction, and functional disabilities. ${ }^{1,2,4,11,12}$ When patients present with sufficient symptomatic deformity, surgical intervention may be warranted.

It is believed that the neurological symptoms seen in cervical kyphosis are a result of deformity-induced anatomical changes that apply pressure to the spinal cord and

\footnotetext{
Abbreviations used in this paper: FCA = focal Cobb angle; GCA $=$ global Cobb angle mJOA = modified Japanese Orthopaedic Association.
}

nerve roots. ${ }^{3,6,11,13}$ Narrowing of the neuroforamen caused by disc degeneration may result in radiculopathy, while stretching or impingement of the spinal cord, often at the apex of the deformity, can lead to myelopathic symptoms. While not all patients with cervical kyphosis present with neurological symptoms, those who do should be carefully monitored. As the kyphosis progresses, spinal cord and nerve root stresses often increase, leading to further neurological debilitation. ${ }^{8,19}$ Despite this observed trend, it is worth noting that a patient's myelopathy may progress even when the kyphosis does not. ${ }^{1,5,10}$

This article contains some figures that are displayed in color online but in black-and-white in the print edition. 
Because of the stresses induced by cervical kyphosis, a number of authors have hypothesized reasons for progressive myelopathy with worsening kyphotic posture, although there is little evidence in the literature to test this. ${ }^{6,9,19,20,24}$ Many have theorized that the tension created from kyphotic deformity on the ventral aspect of the cord results in compression on the regional blood supply and nerves. ${ }^{11}$ The importance of this topic is applicable to deformity correction surgery. Surgeons must balance the risks of attaining increased deformity correction through more invasive surgical techniques, with the conceived benefits of greater deformity correction. In theory, improved outcomes should correlate with the degree of deformity correction, although, once again, the literature

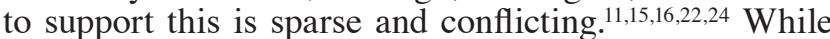
many surgeons believe, at least in theory, that complete correction of a kyphotic spine is best, some authors argue that greater improvements are seen with smaller modifications in sagittal alignment. ${ }^{11}$ The purpose of this study was to determine if the degree of deformity correction correlates with improvement in neurological symptoms following surgery for cervical kyphotic deformity.

\section{Methods}

A single-institution review of patients who underwent cervical deformity surgery for cervical kyphosis between 2000 and 2009 was performed. Approval from the Cleveland Clinic Institutional Review Board was obtained for this study. Of 90 patients with a corresponding ICD-9 code for cervical deformity regardless of medical comorbidity, a total of 36 patients were included in our study. Patients without myelopathic functional deficits related to neurological sequelae (mJOA score $>15$ ) and with less than 2 years of clinical follow-up were excluded from this study. The mean duration of follow-up for the 36 patients was 33 months (range 24-90 months).

We collected information on patient demographics (Table 1), preoperative and postoperative neurological symptoms, and degree of kyphosis. The severity of neurological symptoms was measured using the mJOA scale. ${ }^{7,14}$ While not a direct measurement of neurological

\section{TABLE 1: Patient demographics}

\begin{tabular}{lc}
\hline \multicolumn{1}{c}{ Variable } & Value \\
\hline total no. of patients & 36 \\
male & $22(61 \%)$ \\
female & $14(39 \%)$ \\
mean age & 56.1 \\
mean body mass index & 28.9 \\
no. of patients w/ global kyphotic deformity & 34 \\
no. of patients w/ focal kyphotic deformity & 22 \\
no. of patients w/ previous cervical spine surgery & $18(50 \%)$ \\
surgical approach & \\
$\quad$ dorsal & $13 / 36(34 \%)$ \\
ventral & $3 / 36(8 \%)$ \\
combined & $20 / 36(55 \%)$ \\
\hline
\end{tabular}

status, the mJOA score is a widely used functional grading system developed to reflect the severity of neurological involvement in cervical pathology. ${ }^{7,23}$ The parameters used to assess kyphosis correction were the GCA and the FCA (Figs. 1 and 2). For both parameters, a positive value correlates to kyphosis, and a negative value correlates to lordosis. Preoperative angles were measured on images obtained within 1 month prior to surgery, and postoperative angles were measured using images obtained at least 24 months after surgery. The degree of correction was determined by calculating the difference between the postoperative angle and the preoperative angle. Angles were measured using digital radiographs and PAX workstations by the primary author (M.J.G.).

Based on these radiographic measurements, 34 patients were determined to have global cervical kyphotic deformity, and 22 had focal kyphotic deformity. Global cervical kyphosis was defined as a GCA greater than $0^{\circ}$. Similarly, focal cervical kyphosis was defined by an FCA greater than $0^{\circ}$ and an area of the cervical spine (2-4 levels) in which the majority of the deformity was more pronounced. Two patients had focal kyphosis but an overall lordotic cervical spine, and 20 patients had both global and focal kyphosis.

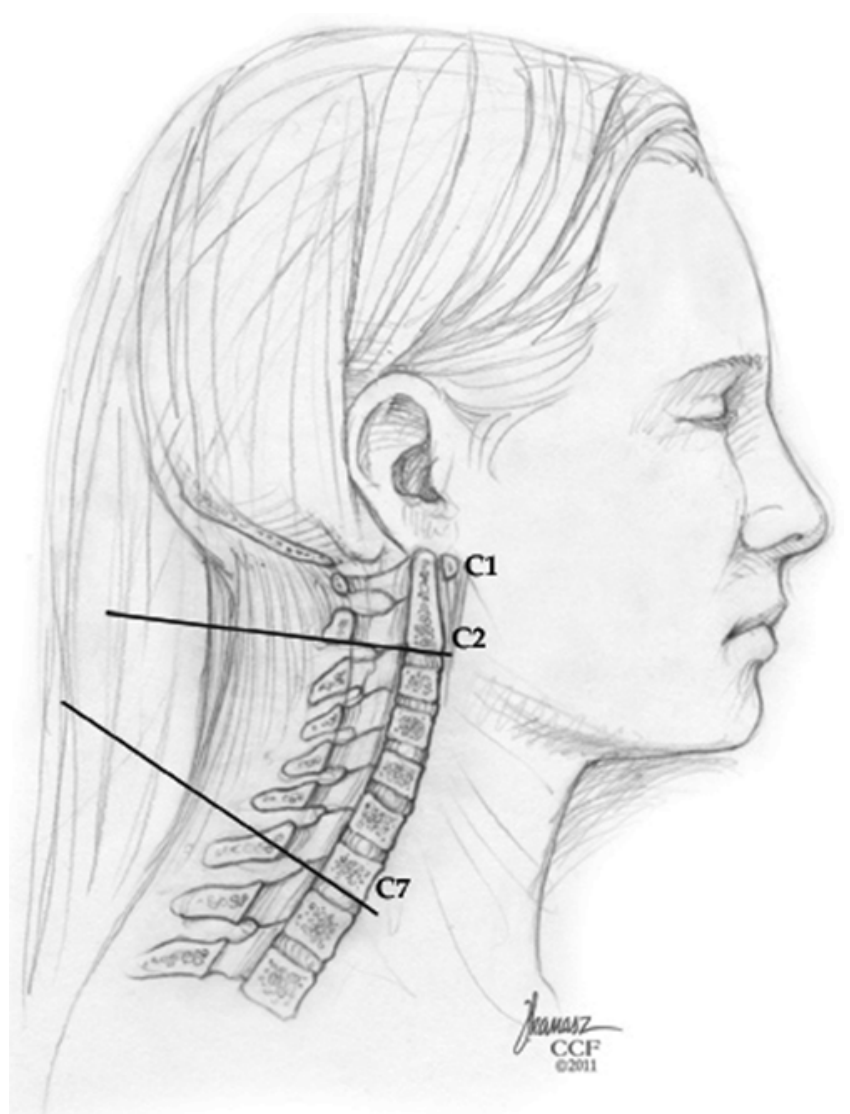

FIg. 1. The GCA is determined by measuring the angle between the inferior aspect of the vertebral levels C-2 and C-7. The FCA is determined using the same method, but the vertebral levels used corresponded to the levels of greatest deformity. Reprinted with permission, Cleveland Clinic Center for Medical Art \& Photography @ (2011-2012. All rights reserved. 


\section{Degree of kyphosis correction and neurological outcome}

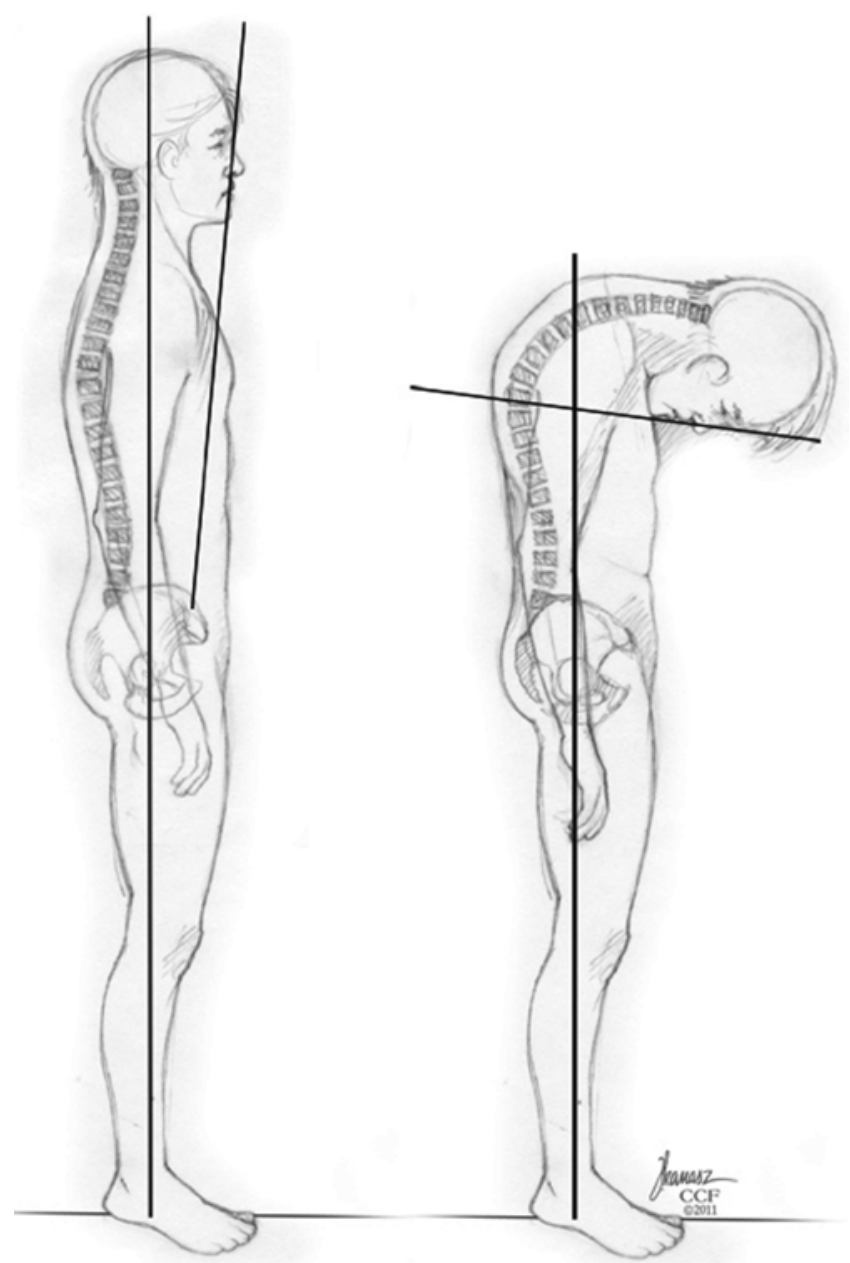

FIG. 2. The chin-brow angle measures the angle between the vertical axis of an upright patient and a line drawn from the chin to the brow. Reprinted with permission, Cleveland Clinic Center for Medical Art \& Photography @ 2011-2012. All rights reserved.

\section{Surgical Techniques}

Surgery was either performed completely ventrally or dorsally or via a combined dorsal and ventral approach. The separate approaches and techniques, which were similar for all cases, will be briefly reviewed. Complete details may be obtained via prior publications. ${ }^{21,22}$ The majority of patients (20 [55\%] of 36) underwent a combined approach, and the remaining patients underwent a dorsal approach alone (13 [37\%] of 36) or ventral approach alone (3 [8\%] of 36) (Table 1). For all procedures, intraoperative multimodal monitoring was used (somatosensory evoked potential monitoring, electromyography, and free-running electromyography).

\section{Ventral Approach}

The ventral approach was used for decompression and correction when the deformity was fixed but the posterior elements were not fused (ankylosed). This approach was also used as part of a combined approach when a rigid deformity requiring ventral and dorsal release was present. The patient was positioned supine. The head was placed on a doughnut or blankets to keep the neck neu- tral (kyphotic position) with care not to extend the neck until ventral decompression and/or osteotomies were performed. Gardner-Wells tongs were placed slightly ventral to their typical location, and initial light pressure was applied (approximately $5 \mathrm{lbs}$ ). A standard approach to the spine was performed as required for decompression and release.

For decompression/release in the ventral approach, we used corpectomy(ies) with or without discectomies. This permits decompression/release while retaining intermediate points of hardware fixation. After decompression/release, many techniques are used to gain correction of the deformity. First, Caspar posts may be placed in a convergent fashion, and distraction placed across these posts affords segmental lordosis. This may be done at multiple levels to gain overall lordosis. Lordotic interbody grafts may be placed to maintain segmental lordosis. Moreover, following release, the doughnut and/or blanket under the patient's head may be removed; extension of the head in traction may significantly gain correction. Lastly, a ventral implant bent into lordosis may be applied and fixated at its rostral and caudal vertebral bodies. Screws may then be placed through the implant and into the intermediate vertebral bodies, and tightening of these screws brings the "spine to the implant."

\section{Dorsal Approach}

A dorsal approach to cervical deformity was used only when the deformity was flexible, specifically when the deformity fully reduces on extension of the cervical spine or in cranial traction. The patient was typically positioned prone in a 3-point headholder. A standard midline subperiosteal approach to the spine was performed. Instrumentation was placed as appropriate to stabilize and correct the deformity. Typically the $\mathrm{C}-2$ pedicle, subaxial lateral mass, and/or upper thoracic pedicle screws were placed. We performed Ponte-type osteotomies at each level through the apex of the deformity. In the cervical spine, these osteotomies consisted of laminectomy and/ or bilateral laminotomy as well as a foraminotomy that was carried all the way along the foramen. Essentially, the existing nerve root was completely unroofed through its foramen. This was performed bilaterally. We placed an elevator into the osteotomy to ensure complete release of bone (movement between lateral masses) before moving on to the next level. With careful management, the 3-point headholder was then released from the operating table, and the head was manually extended, thus closing the dorsal osteotomies and kyphosis. Additionally, after rod placement, compression may be applied across the osteotomies to complete the close and gain further segmental correction.

\section{Combined Ventral/Dorsal Approach}

Commonly, a combined approach is required when there is a need for both dorsal and ventral decompression and/or osteotomies for release. Moreover, dorsal instrumentation is added if the ventral construct is not believed to be adequate for stability such as if only a bridging implant is used. The choice of which approach to use first is 
generally surgeon specific. We typically chose a dorsal approach first followed by ventral release and correction. The ventral approach provides the greatest degree of leverage and overall correction. At times, dorsal instrumentation is present. In these circumstances, a "back, front, back" approach or a similar variety is undertaken (Fig. 3).

\section{Statistical Tests}

Pearson correlation comparisons were run on comparisons of change in GCA versus change in mJOA score, change in FCA versus change in mJOA score, change in GCA versus change in mJOA score for patients with mJOA scores lower than 12, and change in FCA versus change in mJOA score for patients with mJOA scores lower than 12. Student t-tests were used to compare the change in mJOA for the attained lordosis group that attained lordosis versus the group that maintained kyphosis. A $p$ value $<0.05$ was considered significant for all tests.

\section{Results}

\section{Complications}

For the 36 patients in this study, there were 11 perioperative complications in 9 patients $(25 \%)$ (Table 2). The perioperative complications were deep wound infection

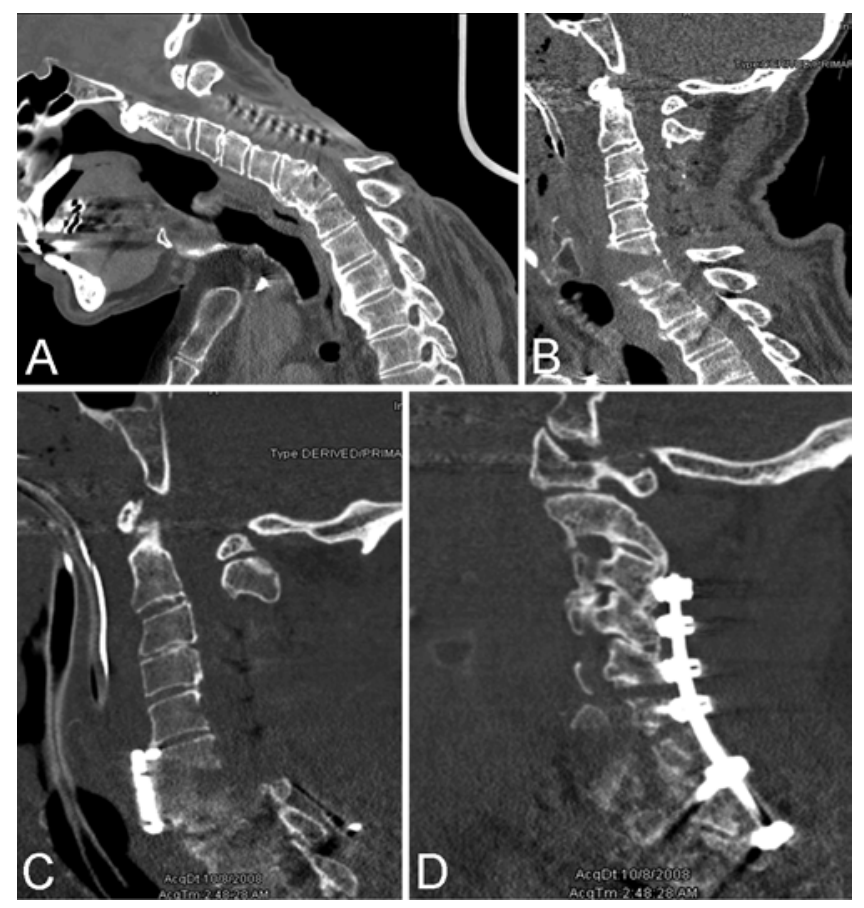

FIG. 3. A: Preoperative CT scan obtained in a 72-year-old patient who developed severe kyphotic deformity focused at C6-7 following a posterior cervical decompression and fusion. B: The patient underwent a multistage combined approach. The first stage consisted of a posterior Smith-Petersen osteotomy, hardware removal, and anterior release. The use of gravity during bed rest for 3 days was sufficient to correct the deformity. C and D: Following correction, an anterior semiconstrained plate was placed, and a posterior exposure was used to place rods in preexisting screws, and compression placed across the Smith-Petersen osteotomies.
( $\mathrm{n}=3,8 \%$ ), deep vein thrombosis $(\mathrm{n}=3,8 \%$ ), pneumonia $(n=3,8 \%)$, and postoperative hematoma $(n=2,6 \%)$. Hardware failure was present in 2 patients $(6 \%$, pedicle screw failure and rod loosening), and pseudarthrosis was observed in $3(8 \%)$. Six patients $(17 \%)$ required revision surgery; 3 of these were required due to infection. The remaining causes of revision surgery were hardware malposition $(n=2)$ and pseudarthrosis $(n=1)$. There were no surgery-related deaths.

\section{Degree of Deformity}

The mean preoperative and postoperative GCAs for patients with global kyphosis were $18.4^{\circ} \pm 14.3^{\circ}$ of kyphosis and $2.8^{\circ} \pm 10.2^{\circ}$ of lordosis, respectively (Table 3 ). The mean change in GCA was $21^{\circ} \pm 15.1^{\circ}$ toward lordosis. Twenty-one patients $(62 \%)$ obtained global neutral or lordotic postures postoperatively.

The mean preoperative and postoperative FCAs for the focal kyphosis patients were $26.0^{\circ} \pm 15.4^{\circ}$ ) of kyphosis and $5.2^{\circ} \pm 8.7^{\circ}$ of kyphosis, respectively (Table 3 ). The mean change in GCA was $21^{\circ} \pm 13.3^{\circ}$ toward lordosis.

The mean preoperative and postoperative FCAs and GCAs by approach are reported in Table 3 . The anterior, posterior, and combined approaches had mean changes in GCA of $17^{\circ}, 17^{\circ}$, and $23.7^{\circ}$ toward lordosis, respectively. The posterior and combined approaches had mean changes in FCA of $10.8^{\circ}$ and $23.6^{\circ}$, respectively.

\section{Neurological Outcomes}

All patients in this study had preoperative myelopathic symptoms, and 10 patients $(28 \%)$ had a concomitant radiculopathy. The mean preoperative and postoperative mJOA scores for the entire cohort were $12.3 \pm 2.0$ and $14.3 \pm 2.5$, respectively, indicating that the mean preoperative patient score was at the threshold between Grade 1 (minimal, mJOA Score 12-15) and Grade 2 (medium, mJOA Score 8-11) neurological symptoms (Table 4). The means for the preoperative and postoperative global kyphosis $(12.3 \pm 2.0$ and $14.3 \pm 2.5$, respectively) and focal kyphosis $(12.1 \pm 1.9$ and $14.1 \pm 2.6$, respectively) groups were similar. Patients with a more severe neurological deficit (mJOA score < 12) saw the greatest improvement in mJOA score (mean improvement 2.5). Based on expert opinion, a difference of 2 points is considered clinically important ${ }^{5}$ Overall, $72 \%$ (26 of 36 patients) saw improvement in mJOA score, $8 \%$ (3 of 36) saw a worsening of symptoms, and $19 \%$ ( 7 of 36) remained the same.

\section{Degree of Deformity Correction Versus Neurological Outcomes}

A significant relationship was observed between a greater degree of focal kyphosis correction and improved neurological outcomes according to the mJOA score ( $\mathrm{r}$ $=-0.46, p=0.032$ ) (Fig. 4 upper). This relationship was not significant when looking at the GCA $(r=-0.12, p=$ $0.50)$ (Fig. 4 lower). For patients with severe neurological symptoms (mJOA score < 12), a trend toward improved outcomes with greater global kyphosis correction was observed $(\mathrm{r}=-0.56, \mathrm{p}=0.057$ ) (Fig. 5 lower). A significant correlation for greater focal kyphosis correction and neu- 


\section{Degree of kyphosis correction and neurological outcome}

TABLE 2: Complications

\begin{tabular}{|c|c|}
\hline Variable & Value $^{*}$ \\
\hline perioperative complications (36 patients) & 11 complications in 9 patients ( $25 \%)$ \\
\hline most common perioperative complications & $\begin{array}{l}\text { deep wound infection }(n=3,8 \%) \text {, deep vein thrombosis }(n=3,8 \%) \text {, pneumonia } \\
\quad(n=3,8 \%) \text {, postop hematoma }(n=2,6 \%)\end{array}$ \\
\hline \multicolumn{2}{|l|}{ long-term complications } \\
\hline postop hardware malposition & $2 / 36(6 \%)$ \\
\hline pseudarthrosis & $3 / 36(8 \%)$ \\
\hline revision surgery & $6 / 36(17 \%)$ \\
\hline \multicolumn{2}{|l|}{ complications by approach } \\
\hline anterior & deep vein thrombosis $(n=1)$, pneumonia $(n=1)$ \\
\hline posterior & deep vein thrombosis $(n=1)$, postop hematoma $(n=1)$ \\
\hline combined & $\begin{array}{l}\text { deep wound infection }(n=3) \text {, deep vein thrombosis }(n=1) \text {, pneumonia }(n=2) \text {, } \\
\text { postop hematoma }(n=1)\end{array}$ \\
\hline
\end{tabular}

* $n=$ number of cases.

rological improvement was observed for this severe group as well ( $\mathrm{r}=-0.72, \mathrm{p}<0.01)$ (Fig. 5 upper).

Patients who attained global lordosis postoperatively had a mean improvement in total mJOA score of 2.7. This was significantly higher compared with patients who maintained a kyphotic cervical spine (mean improvement $1.1, \mathrm{p}=0.044$ ) (Table 5). Both patient groups had similar preoperative mJOA scores (a mean of 12.1 for those achieving lordosis and a mean of 12.8 for those maintaining kyphosis).

\section{Discussion}

Kyphosis of the cervical spine can be a debilitating condition that leads to significant neurological dysfunction. In cases of progressively symptomatic cervical kyphotic deformity, deformity correction surgery is an option. Recent studies have shown the efficacy of surgery for treating this condition, but many questions remain in determining the appropriate corrective strategy. ${ }^{6,10}$ In theory, the degree of deformity should correlate with neurological dysfunction. This would also suggest that greater deformity correction from surgery can lead to better outcomes. However, this theory has never been thoroughly tested. Our study found that the degree of correction of focal kyphosis deformity correlates with improved neurological outcomes.

While the extent of kyphosis is commonly associated with progression of neurological symptoms, there is surprisingly little evidence to support this claim. A commonly hypothesized reason for this observation comes from the notion of a bowstring effect on the spinal cord, which worsens with increased bending of kyphosis. ${ }^{6,9,13}$ Based on this theory it is reasonable to assume that a greater degree of correction may be associated with improved outcomes.

To our knowledge, this is the first study to extensively examine the relationship between the degree of correction and neurological outcomes. One study by Ferch and colleagues ${ }^{11}$ examined improvement in myelopathic scores for patients who underwent ventral corrective surgery and achieved deformity correction, defined as $0^{\circ}-4^{\circ}$ of lordosis. The authors found that patients who achieved both global and local lordotic posture had a better chance of

TABLE 3: Degree of deformity

\begin{tabular}{cccc}
\hline & \multicolumn{3}{c}{ Mean \pm SD $^{*}$} \\
\cline { 2 - 4 } Type of Deformity \& Approach & Preop & Postop & \\
\hline GCA & & $1.8 \pm 7.5$ & $-17.0 \pm 13.2$ \\
anterior (3 cases) & $19.3 \pm 15.5$ & $-2.0 \pm 3.0$ & $-17.0 \pm 8.2$ \\
posterior (12 cases) & $15.0 \pm 11.1$ & $-5.7 \pm 11.5$ & $-23.7 \pm 16.9$ \\
combined (19 cases) & $18.4 \pm 14.6$ & $-2.8 \pm 10.2$ & $-21 \pm 15.1$ \\
overall (34 cases) & $18.4 \pm 14.3$ & & \\
FCA & & & $-10.8 \pm 13.0$ \\
anterior (0 cases) & & $10.4 \pm 8.8$ & $-23.6 \pm 12.6$ \\
posterior (10 cases) & $22.4 \pm 11.8$ & $2.5 \pm 8.0$ & $-21 \pm 13.3$ \\
combined (12 cases) & $25.3 \pm 13.3$ & $5.2 \pm 8.7$ & \\
overall (22 cases) & $26.0 \pm 15.4$ & & \\
\hline
\end{tabular}

* Values are in degrees. 


\begin{tabular}{cccc}
\hline & \multicolumn{3}{c}{ mJOA Score } \\
\cline { 2 - 3 } Type of Deformity & Preop & Postop & Change \\
\hline GCA (34 cases) & $12.3 \pm 2.0$ & $14.3 \pm 2.5$ & $2.0 \pm 2.1$ \\
FCA (22 cases) & $12.1 \pm 1.9$ & $14.1 \pm 2.6$ & $2.0 \pm 1.9$ \\
\hline * Values are presented as the mean \pm SD. Overall, $26(72 \%)$ of the 36 patients improved, $7(19 \%)$ remained the same, and 3 (8\%) \\
deteriorated.
\end{tabular}

improvement in their myelopathic scores compared with those who did not $(p=0.04)$. Our study confirmed these findings in our comparison of change in mJOA scores for those patients who achieved global lordosis and those who maintained global kyphosis $(\mathrm{p}=0.044)$. In addition, we took this a step further to attempt to correlate a range of correction degrees with improvements in neurological function. We found that a greater degree of focal kyphosis correction was associated with a greater degree of neurological improvement $(\mathrm{p}=0.032)$, as well as a trend toward this relationship for global kyphosis correction in patients with severe neurological symptoms $(\mathrm{p}=0.057)$. This relationship is important in the context of surgical management, as it gives the surgeon one more piece of information to help guide his or her surgical strategy de-
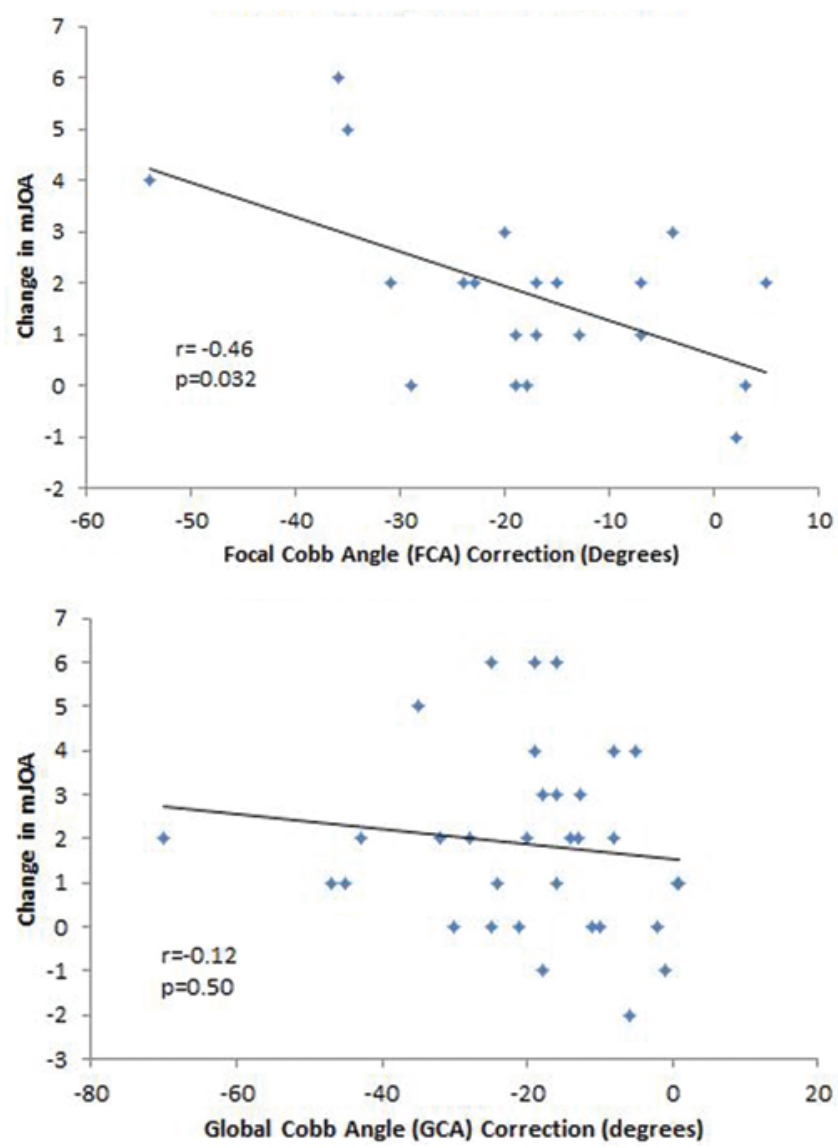

FIG. 4. Upper: A significant correlation $(p<0.05)$ was observed between the degree of focal kyphosis correction achieved and change in mJOA score. Lower: No correlation between the degree of global kyphosis correction and change in mJOA score was observed. cision making. Although the mean degree of correction was similar for global kyphosis and focal kyphosis $\left(21^{\circ}\right)$, we did not find a significant relationship between the degree of correction of global kyphosis and neurological outcome. This indicates that for global kyphosis in our patient cohort, improved correction did not necessarily reflect improved outcomes. This difference between the impact of global and focal kyphosis correction is unclear. One possible explanation is that focal kyphosis is a more direct indicator of spinal cord strain, and, therefore, focal improvement is a stronger correlate to spinal cord stress and neurological improvement than global correction.

For patients with severe neurological symptoms (mJOA score < 12) there was an even more pronounced
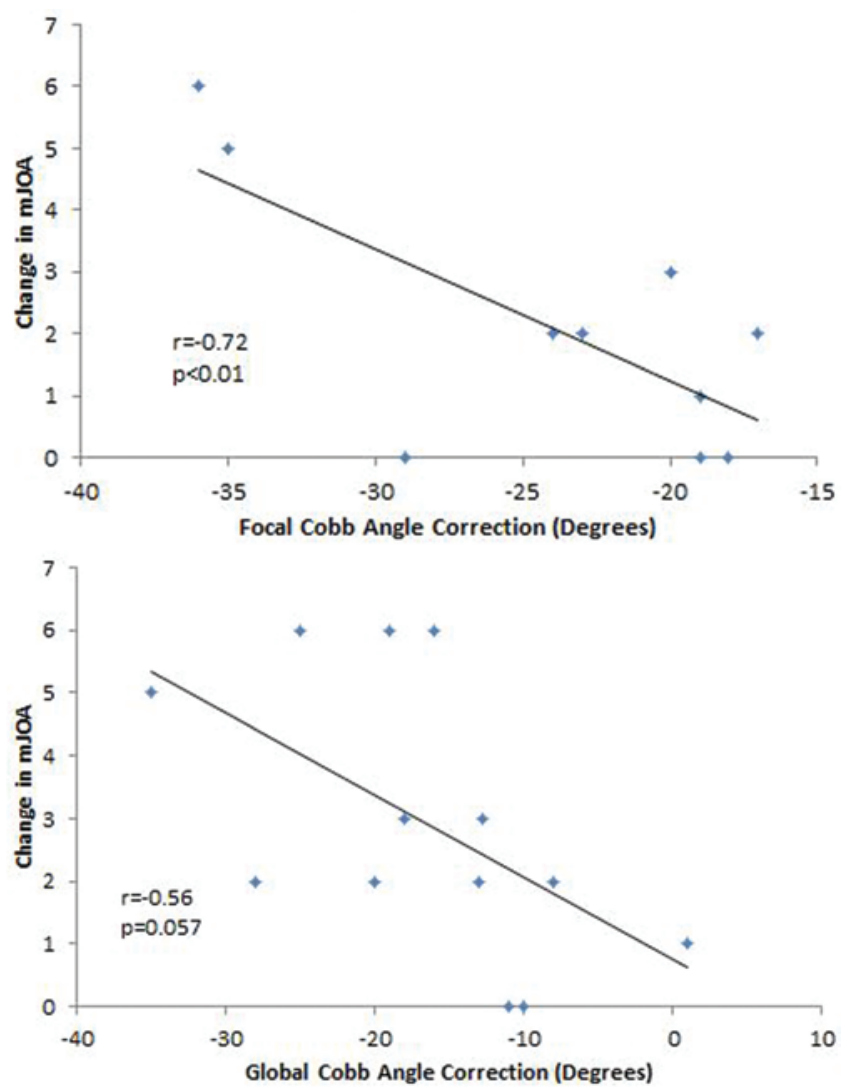

FIG. 5. Upper: A significant correlation $(p<0.05)$ was observed between the degree of focal kyphosis correction achieved and change in $\mathrm{mJOA}$ score for patients with more severe neurological symptoms (mJOA score < 12). Lower: A nonsignificant trend $(p=0.057)$ was observed between the degree of focal kyphosis correction achieved and change in $\mathrm{mJOA}$ score for patients with more severe neurological symptoms (mJOA score < 12). 


\section{Degree of kyphosis correction and neurological outcome}

TABLE 5: Lordosis achieved and neurological outcome*

\begin{tabular}{lc}
\hline \multicolumn{1}{c}{ GCA Deformity } & Change in mJOA \\
\hline maintained kyphosis (13 cases) & $1.1 \pm 2.1$ \\
achieved lordosis (21 cases) & $2.7 \pm 2.0$ \\
p value & 0.044 \\
\hline
\end{tabular}

* Mean values are presented as the mean \pm SD.

relationship between focal correction and improvement in mJOA score $(r=-0.72, p<0.01)$. For this subgroup, global correction may play an important role as well $(\mathrm{r}=$ $-0.56, p=0.057)$. Because of the small sample size for this analysis $(n=13)$, further studies investigating this patient population are warranted.

We would like to stress that the results do not suggest that greater deformity correction always equates with better outcomes. The risks associated with achieving cervical spine deformity correction are significant, and they must be carefully weighed with the benefits of possible neurological improvement. For example, greater correction, while perhaps reducing tension from the kyphotic position, may increase the chance of cord distraction in the lordotic position causing the cord to be under axial strain. ${ }^{11}$ In the study by Ferch et al., ${ }^{11}$ the authors reported that the one patient who achieved the greatest local correction per level fused also was the only patient whose myelopathy deteriorated postoperatively. They concluded that smaller modifications might be most effective in achieving greater improvement in cord function. Although this may be the case, it is worth noting that none of our top 5 patients who achieved the greatest degrees of postoperative focal or global lordosis (up to $18^{\circ}$ ) saw deterioration in neurological symptoms. Nevertheless, it is clear that the risks and benefits must be carefully assessed on an individual patient basis.

As mentioned, our study was limited by the fact that we did not attempt to determine this range of ideal correction, given that too much correction may be detrimental. In addition, this study carries the weaknesses of a retrospective study utilizing a heterogeneous population. It is possible that patients who achieved less deformity correction had more comorbidities or had other differences that could have affected neurological outcomes. Given these limitations, the results from this study should only be used in context with the other factors in cervical deformity correction surgery.

\section{Conclusions}

In patients with focal kyphosis, a greater degree of correction may assist in achieving greater neurological improvements. In addition, in correction surgery for cervical kyphotic deformity, better outcomes were reported in patients who achieved lordosis than in those who maintained kyphosis. With consideration for the risks involved in correction surgery, this information can be used to help guide surgical strategy decision making.

\section{Disclosure}

Dr. Mroz is a consultant for Globus; has direct stock ownership in PearlDiver, Inc.; and receives honoraria and fellowship support from AOSpine North America. Dr. Steinmetz is a consultant for Biomet Spine. The authors report no conflict of interest concerning the materials or methods used in this study or the findings specified in this paper.

Author contributions to the study and manuscript preparation include the following. Conception and design: all authors. Acquisition of data: Steinmetz, Grosso, Hwang. Analysis and interpretation of data: Steinmetz, Grosso, Mroz, Benzel. Drafting the article: Steinmetz, Grosso. Critically revising the article: all authors. Reviewed submitted version of manuscript: all authors. Approved the final version of the manuscript on behalf of all authors: Steinmetz. Statistical analysis: Steinmetz, Grosso. Administrative/technical/material support: Grosso. Study supervision: Steinmetz, Grosso.

\section{References}

1. Albert TJ, Vacarro A: Postlaminectomy kyphosis. Spine (Phila Pa 1976) 23:2738-2745, 1998

2. Anderson DG, Silber JS, Albert TJ: Management of cervical kyphosis caused by surgery, degenerative disease, or trauma, in Clark CR (ed): The Cervical Spine, ed 4. Philadelphia: Lippincott Williams \& Wilkins, 2005, pp 1135-1146

3. Azuma S, Seichi A, Ohnishi I, Kawaguchi H, Kitagawa T, Nakamura K: Long-term results of operative treatment for cervical spondylotic myelopathy in patients with athetoid cerebral palsy: an over 10-year follow-up study. Spine (Phila Pa 1976) 27:943-948, 2002

4. Baptiste DC, Fehlings MG: Pathophysiology of cervical myelopathy. Spine J 6 (6 Suppl):190S-197S, 2006

5. Bartels RH, Verbeek ALM, Grotenhuis JA: Design of Lamifuse: a randomised, multi-centre controlled trial comparing laminectomy without or with dorsal fusion for cervical myeloradiculopathy. BMC Musculoskelet Disord 8:111, 2007

6. Batzdorf U, Batzdorff A: Analysis of cervical spine curvature in patients with cervical spondylosis. Neurosurgery 22:827836,1988

7. Benzel EC, Lancon J, Kesterson L, Hadden T: Cervical laminectomy and dentate ligament section for cervical spondylotic myelopathy. J Spinal Disord 4:286-295, 1991

8. Brain WR, Northfield D, Wilkinson M: The neurological manifestations of cervical spondylosis. Brain 75:187-225, 1952

9. Dai L: Disc degeneration and cervical instability. Correlation of magnetic resonance imaging with radiography. Spine (Phila Pa 1976) 23:1734-1738, 1998

10. Etame AB, Than KD, Wang AC, La Marca F, Park P: Surgical management of symptomatic cervical or cervicothoracic kyphosis due to ankylosing spondylitis. Spine (Phila Pa 1976) 33:E559-E564, 2008

11. Ferch RD, Shad A, Cadoux-Hudson TAD, Teddy PJ: Anterior correction of cervical kyphotic deformity: effects on myelopathy, neck pain, and sagittal alignment. J Neurosurg 100 (1 Suppl Spine):13-19, 2004

12. Grob D, Frauenfelder H, Mannion AF: The association between cervical spine curvature and neck pain. Eur Spine J 16:669678,2007

13. Herman JM, Sonntag VKH: Cervical corpectomy and plate fixation for postlaminectomy kyphosis. J Neurosurg 80:963970, 1994

14. Hukuda S, Mochizuki T, Ogata M, Shichikawa K, Shimomura Y: Operations for cervical spondylotic myelopathy. A comparison of the results of anterior and posterior procedures. J Bone Joint Surg Br 67:609-615, 1985

15. Kaptain GJ, Simmons NE, Replogle RE, Pobereskin L: Incidence and outcome of kyphotic deformity following laminectomy for cervical spondylotic myelopathy. J Neurosurg 93 (2 Suppl):199-204, 2000

16. Laing RJ, Ng I, Seeley HM, Hutchinson PJ: Prospective study of clinical and radiological outcome after anterior cervical discectomy. Br J Neurosurg 15:319-323, 2001 


\section{J. Grosso et al.}

17. Miyazaki M, Hong SW, Yoon SH, Zou J, Tow B, Alanay A, et al: Kinematic analysis of the relationship between the grade of disc degeneration and motion unit of the cervical spine. Spine (Phila Pa 1976) 33:187-193, 2008

18. Miyazaki M, Hymanson HJ, Morishita Y, He W, Zhang H, $\mathrm{Wu} \mathrm{G}$, et al: Kinematic analysis of the relationship between sagittal alignment and disc degeneration in the cervical spine. Spine (Phila Pa 1976) 33:E870-E876, 2008

19. Nurick S: The pathogenesis of the spinal cord disorder associated with cervical spondylosis. Brain 95:87-100, 1972

20. Sim FH, Svien HJ, Bickel WH, Janes JM: Swan-neck deformity following extensive cervical laminectomy. A review of twenty-one cases. J Bone Joint Surg Am 56:564-580, 1974

21. Steinmetz MP, Kager CD, Benzel EC: Ventral correction of postsurgical cervical kyphosis. J Neurosurg 98 (1 Suppl): $1-7,2003$

22. Steinmetz MP, Stewart TJ, Kager CD, Benzel EC, Vaccaro AR: Cervical deformity correction. Neurosurgery 60 (1 Suppl 1): S90-S97, 2007

23. Vitzthum HE, Dalitz K: Analysis of five specific scores for cervical spondylogenic myelopathy. Eur Spine J 16:20962103, 2007

24. Zdeblick TA, Bohlman HH: Cervical kyphosis and myelopathy. Treatment by anterior corpectomy and strut-grafting. J Bone Joint Surg Am 71:170-182, 1989

Manuscript submitted May 24, 2012.

Accepted February 18, 2013.

Portions of this work were presented in poster form at the Congress of Neurological Surgeons 2011 Annual Meeting, October 1-6, 2011, Washington, DC, and Cervical Spine Research Society 39th Annual Meeting, December 7, 2011, Scottsdale, Arizona.

Please include this information when citing this paper: published online April 5, 2013; DOI: 10.3171/2013.2.SPINE12525.

Address correspondence to: Michael Steinmetz, M.D., Department of Neuroscience, The MetroHealth System, 2500 MetroHealth Drive, Cleveland, Ohio 44109. email: msteinmetz@metrohealth.org. 